\title{
(2) OPEN ACCESS \\ Place of death of children and young adults with a life-limiting condition in England: a retrospective cohort study
}

\author{
Deborah Gibson-Smith, Stuart William Jarvis 도 , Lorna K Fraser
}

- Additional material is published online only. To view please visit the journal online (http://dx.doi.org/10.1136/ archdischild-2020-319700)

Health Sciences, University of York, York, UK

\section{Correspondence to}

Professor Lorna K Fraser, Health Sciences, University of York, York Y010 5DD, UK:

lorna.fraser@york.ac.uk

Received 17 May 2020 Revised 20 November 2020 Accepted 30 November 2020 Published Online First 21 December 2020

\section{Check for updates}

(c) Author(s) (or their employer(s)) 2021. Re-use permitted under CC BY. Published by BMJ.

To cite: Gibson-Smith D,

Jarvis SW, Fraser LK.

Arch Dis Child

2021:106:780-785

\begin{abstract}
Objective To assess trends in place of death for children with a life-limiting condition and the factors associated with death at home or hospice rather than hospital.

Design Observational cohort study using linked routinely collected data.

Setting England.

Patients Children aged $0-25$ years who died between 2003 and 2017.

Main outcome measures Place of death: hospital, hospice, home. Multivariable multinomial logistic regression models.
\end{abstract}

Results 39349 children died: $73 \%$ occurred in hospital, $6 \%$ in hospice and $16 \%$ at home. In the multivariable models compared with dying in a hospital: neonates were less likely, and those aged 1-10 years more likely, than those aged 28 days to $<1$ year to die in hospice. Children from all ethnic minority groups were significantly less likely to die in hospice, as were those in the most deprived group ( $\mathrm{RR} 0.8,95 \% \mathrm{Cl} 0.7$ to 0.9 ). Those who died from 2008 were more likely than those who died earlier to die in a hospice.

Children with cancer (RR 4.4, 95\% Cl 3.8 to 5.1), neurological (RR 2.0,95\% Cl 1.7 to 2.3 ) or metabolic (RR 3.7, 95\% Cl 3.0 to 4.6) diagnoses were more likely than those with a congenital diagnosis to die in a hospice.

Similar patterns were seen for clinical/demographic factors associated with home versus hospital deaths. Conclusions Most children with a life-limiting condition continue to die in the hospital setting. Further research on preferences for place of death is needed especially in children with conditions other than cancer. Paediatric palliative care services should be funded adequately to enable equal access across all settings, diagnostic groups and geographical regions.

\section{INTRODUCTION}

Although deaths in childhood have been decreasing, there are still 4500 infants and children who die in England and Wales every year ${ }^{1}$ and approximately $50 \%$ of deaths in children ${ }^{2}$ are for children with a life-limiting or life-threatening condition. Access to palliative and end-of-life care are therefore important components of paediatric health services. $^{3}$

Palliative care services for children and young people in the UK have developed locally with heavy reliance on individual clinicians and third sector organisations such as children's hospices. ${ }^{3}$ That

\section{What is already known on this topic?}

Place of death is used as a quality measure of end-of-life care.

- More children die at home or in hospice setting if they have palliative care input.

- The current evidence states that most parents, children and providers prefer home death.

\section{What this study adds?}

- The vast majority of children with a life-limiting condition continue to die in the hospital setting.

- Children with a cancer diagnosis are much more likely to die at home or in hospice than children with other life-limiting conditions.

ad hoc provision means delivery of palliative care is often 'inconsistent and incoherent'. 4 The recent NICE guidelines ${ }^{5}$ and quality standards of providing care $^{6}$ include: 'Infants, children and young people approaching the end of life and being cared for at home have 24 hour access to both children's nursing care and advice from a consultant in paediatric palliative care'. Currently in England, while there are more than 50 children's hospices, there are even tertiary children's hospitals, including oncology centres, without a paediatric palliative care service.

Place of death has been used in policy documentation as a measure of quality of palliative or end-of-life care in developed countries such as the UK. ${ }^{7}$ The assumption that everyone wants to die at home has been contested in both children's and adult palliative care in recent years. ${ }^{89} \mathrm{~A}$ recent review has concluded that 'Most parents, children, and providers prefer home death and the long-term outcomes for parents (even 6-8 years after the death of their child) may be better when their child died at home' but the authors also acknowledge that not all parents prefer a home death and the evidence is often from small studies. ${ }^{10}$ However, at a population level, if we are truly able to offer choice of place of care at the end of life then we should see a spread between the possible places of death. One of the aims of recent NHS England service specification for palliative care is that 'more children and young people will achieve their preferred place of care at the end of their lives'. A national study showed that children who had palliative care input were eight times as likely as those without palliative 
care input to die in the community rather than in hospital. ${ }^{11}$ Therefore, the distribution of deaths between hospital, home and hospice may provide an indication of the degree to which families are able to access palliative care.

\section{Aims and objectives}

This study aims to assess the trends in place of death for children who died with a life-limiting condition in England from 2003 to 2017 and the clinical and demographic factors which are associated with death at home or hospice rather than hospital.

\section{METHODS}

\section{Data sources}

Linked individual-level inpatient Hospital Episode Statistics (HES) and Office for National Statistics (ONS) death records were obtained from NHS Digital. These two data sets were linked by NHS Digital based on National Health Service number, gender date of birth and postcode. ${ }^{12} 13$ Children and young people with a life-limiting condition were identified by matching recorded diagnostic codes in inpatient records against the previously developed ICD-10 coding framework ${ }^{14}$ (online supplemental table 1), for individuals aged 0-25 years (1 January 2000 to 31 December 2017).

\section{Data management}

Place of death was categorised as hospital, hospice, home, other and missing based on the recorded address of death in the ONS death certificate data. The 'other' category included deaths at respite care centres, nursing homes, deaths outside the home (eg, in a park or school). Deaths where the street address was not present were recorded as missing.

The year of death was assigned from the ONS death certificate date of death and the sex was assigned as the most commonly recorded sex from the HES data.

Age of death at last birthday was calculated by subtracting date of birth (HES record) from date of death (ONS record). Those who had died in the neonatal period ( $<28$ days) were flagged on the death record. Seven age groups were created: neonate $<28$

Table 1 Demographic characteristics of children and young people with a life-limiting condition who died*

\begin{tabular}{|c|c|c|c|c|c|c|c|c|c|}
\hline & \multicolumn{2}{|c|}{ Hospital } & \multicolumn{2}{|c|}{ Hospice } & \multicolumn{2}{|l|}{ Home } & \multicolumn{2}{|c|}{ Other or missingt } & \multirow{2}{*}{$\frac{\text { Total }}{n}$} \\
\hline & $n$ & $\%$ & $n$ & $\%$ & $\mathrm{n}$ & $\%$ & $n$ & $\%$ & \\
\hline Total & 28753 & 73 & 2453 & 6 & 6269 & 16 & 1874 & 5 & 39349 \\
\hline \multicolumn{10}{|l|}{ Sex } \\
\hline Male & 15846 & 73 & 1332 & 6 & 3579 & 16 & 1066 & 5 & 21823 \\
\hline Female & 12885 & 74 & 1121 & 6 & 2689 & 15 & 750 & 4 & 17445 \\
\hline \multicolumn{10}{|l|}{ Age group at death } \\
\hline Neonate (<28 days) & 9511 & 97 & 163 & 2 & 171 & 2 & & & 9846 \\
\hline 28 days to 1 year & 5586 & 71 & 380 & 5 & 614 & 8 & 1301 & 17 & 7881 \\
\hline $1-5$ years & 3498 & 68 & 488 & 10 & 1063 & 21 & 79 & 2 & 5128 \\
\hline $6-10$ years & 1554 & 57 & 295 & 11 & 819 & 30 & 48 & 2 & 2716 \\
\hline $11-15$ years & 1772 & 59 & 302 & 10 & 856 & 29 & 68 & 2 & 2998 \\
\hline $16-20$ years & 3010 & 63 & 347 & 7 & 1266 & 27 & 138 & 3 & 4761 \\
\hline $21-25$ years & 3822 & 63 & 478 & 8 & 1480 & 25 & 239 & 4 & 6019 \\
\hline \multicolumn{10}{|l|}{ Ethnic group } \\
\hline White & 18017 & 69 & 1973 & 8 & 5030 & 19 & 949 & 4 & 25969 \\
\hline Black & 1937 & 83 & 73 & 3 & 187 & 8 & 136 & 6 & 2333 \\
\hline Pakistani & 2521 & 84 & 99 & 3 & 301 & 10 & 93 & 3 & 3014 \\
\hline Indian & 888 & 81 & 39 & 4 & 117 & 11 & 47 & 4 & 1091 \\
\hline Bangladeshi & 544 & 85 & 16 & 2 & 61 & 9 & 22 & 3 & 643 \\
\hline Mixed/Chinese/other & 2393 & 78 & 167 & 5 & 340 & 11 & 175 & 6 & 3075 \\
\hline \multicolumn{10}{|l|}{ Region } \\
\hline North-East & 1227 & 71 & 60 & 4 & 392 & 23 & 58 & 3 & 1737 \\
\hline North-West & 4100 & 75 & 292 & 5 & 889 & 16 & 211 & 4 & 5492 \\
\hline Yorkshire and Humber & 2745 & 71 & 361 & 9 & 663 & 17 & 122 & 3 & 3891 \\
\hline East Midlands & 2212 & 75 & 153 & 5 & 512 & 17 & 87 & 3 & 2964 \\
\hline West Midlands & 3270 & 75 & 291 & 7 & 661 & 15 & 164 & 4 & 4386 \\
\hline East of England & 2435 & 68 & 295 & 8 & 710 & 20 & 120 & 3 & 3560 \\
\hline London & 4874 & 77 & 267 & 4 & 775 & 12 & 423 & 7 & 6339 \\
\hline South-East & 3631 & 69 & 457 & 9 & 985 & 19 & 219 & 4 & 5292 \\
\hline South-West & 2136 & 68 & 250 & 8 & 626 & 20 & 119 & 4 & 3131 \\
\hline \multicolumn{10}{|l|}{ Deprivation category } \\
\hline Category 1 (least deprived) & 3179 & 66 & 431 & 9 & 1071 & 22 & 156 & 3 & 4837 \\
\hline Category 2 & 3866 & 68 & 454 & 8 & 1186 & 21 & 220 & 4 & 5726 \\
\hline Category 3 & 4851 & 70 & 495 & 7 & 1287 & 19 & 294 & 4 & 6927 \\
\hline Category 4 & 6096 & 74 & 507 & 6 & 1302 & 16 & 325 & 4 & 8230 \\
\hline Category 5 (most deprived) & 7851 & 78 & 533 & 5 & 1339 & 13 & 409 & 4 & 10132 \\
\hline
\end{tabular}

*Those with missing deomgraphics are not presented due to small numbers.

tCombined to prevent small numbers. 


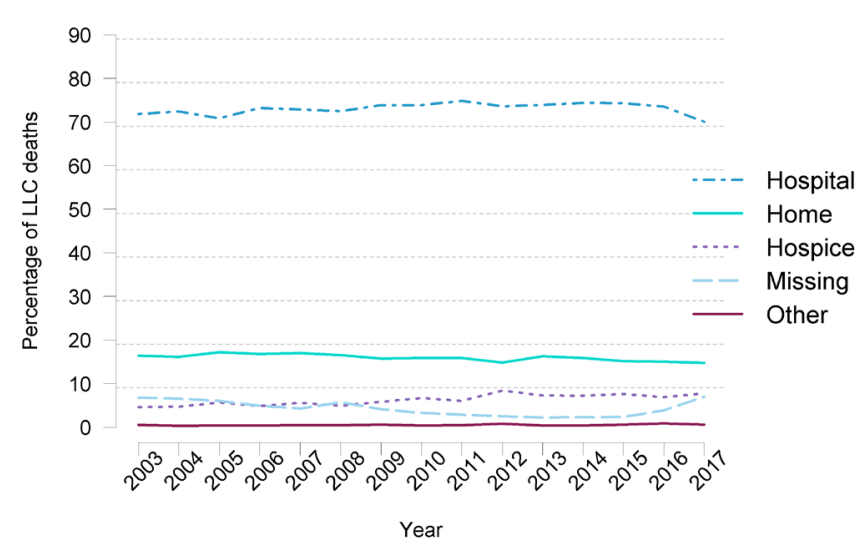

Figure 1 Trends in place of death of children and young people with a life-limiting condition in England from 2003 to 2017. LLC, life-limiting or life-threatening condition.

days, 28 days -1 year, 1-5 years, 6-10 years, 11-15 years, 16-20 years and 21-25 years.

Self-reported ethnicity for each hospital episode was coded according to the 16 census groups; ${ }^{15}$ to prevent small numbers, these groups were collapsed into six ethnic groups as follows with the most commonly recorded ethnicity (from the six collapsed groups) assigned to each individual:

- White (white: British, white: Irish, other white)

- Black (black or black British: black Caribbean, black or black British: black African, black or black British: other black)

- Indian (Asian or Asian British: Indian)

- Pakistani (Asian or Asian British: Pakistani)

- Bangladeshi (Asian or Asian British: Bangladeshi)

- Other (Chinese, mixed or other)

The last known government office region of residence was assigned using the HES and ONS data for each individual.

An Index of Multiple Deprivation (IMD2010) Score ${ }^{16}$ was assigned to each individual based on last known lower super output area (LSOA) of residence. LSOAs are small geographical areas with a population from 1000 to 3000 individuals. Five population-weighted categories were created (category 1-least deprived) based on the IMD Scores with approximately $20 \%$ of the population living in each category.

The life-limiting condition diagnoses were grouped according to 11 diagnostic groups (neurology, haematology, oncology, metabolic, respiratory, circulatory, gastrointestinal, genitourinary, perinatal, congenital and other). ${ }^{14}$ The most common diagnostic group across all inpatient records for each individual was calculated with ties resolved by giving preference to later diagnoses.

\section{Analysis}

To avoid missing data issue at the start of the study time period, children were included in the analyses 2003 onwards.

Temporal trends in place of death were plotted as a visual assessment of change over time. Place of death was described by sex, age group, ethnicity, government office region, deprivation category and main diagnostic group.

The association between the place of death and key clinical (diagnostic group) and demographic (age, sex, ethnic group, deprivation status and region) variables was assessed using multivariable multinomial logistic regression modelling comparing hospital death to both home and hospice deaths. Year of death was included in three equal epochs: 2003-2007, 2008-2012 and 2013-2017. ${ }^{17}$

All data manipulation was undertaken using Microsoft SQL server and statistical analysis using STATA V.15 (StataCorp, Collage Station, Texas, USA). Statistical significance was assumed at $\mathrm{p} \leq 0.05$ (two-sided).

\section{RESULTS}

\section{Cohort}

The total cohort of children with a life-limiting condition who had died from 2000 to 2017 was 53 518. After removal of those not resident in England $(n=1512)$ and those who died before 2003 or after $2017(n=7853)$ and those who died $>25$ years $(n=4804)$, the final cohort for analyses was 39349 .

\section{Place of death}

Overall $73 \%$ of deaths occurred in hospital, $6 \%$ in hospice and $16 \%$ at home. Five per cent died elsewhere or were missing place of death (table 1).

The percentage of deaths in hospital remained relatively static at just over $70 \%$ of deaths (figure 1). The percentage of children who died at home remained relatively static at around $15 \%-16 \%$. This was in contrast to deaths in hospices which rose from $5 \%$ to $8 \%$ during the period of this study.

Place of death varied considerably by age with $97 \%$ of neonates and $71 \%$ of those aged 28 days to 1 year dying in hospital and only $2 \%$ and $8 \%$, respectively, dying at home (table 1 ). The percentage of children dying at home peaks at 30\% in those aged 6-10 years. Deaths in hospices were also most common, at $11 \%$, in the $6-10$ years age group.

Table 2 Clinical characteristics of children and young people with a life-limiting condition who died

\begin{tabular}{|c|c|c|c|c|c|c|c|c|c|}
\hline \multirow[b]{2}{*}{ Cancer } & \multicolumn{3}{|c|}{ Hospital } & \multirow{2}{*}{$\begin{array}{l}\text { Hospice } \\
14\end{array}$} & \multicolumn{2}{|l|}{ Home } & \multicolumn{2}{|c|}{ Other or missing ${ }^{*}$} & \multirow{2}{*}{$\begin{array}{r}\text { Total } \\
7914\end{array}$} \\
\hline & 3515 & 44 & 1075 & & 3224 & 41 & 100 & 1 & \\
\hline Metabolic conditions & 830 & 61 & 179 & 13 & 306 & 23 & 36 & 3 & 1351 \\
\hline Other conditions & 530 & 71 & 73 & 10 & 92 & 12 & 51 & 7 & 746 \\
\hline Circulatory conditions & 8276 & 81 & 425 & 4 & 917 & 9 & 621 & 6 & 10239 \\
\hline Genitourinary conditions & 1775 & 82 & 44 & 2 & 196 & 9 & 160 & 7 & 2175 \\
\hline Congenital conditions & 1074 & 86 & 20 & 2 & 105 & 8 & 46 & 4 & 1245 \\
\hline Gastrointestinal conditions & 475 & 88 & 11 & 2 & 25 & 5 & 30 & 6 & 541 \\
\hline Perinatal conditions & 6566 & 90 & 86 & 1 & 133 & 2 & 540 & 7 & 7325 \\
\hline
\end{tabular}

${ }^{*}$ Combined due to small numbers. 
Table 3 Multivariable multinomial logistic models $(n=34425)$

\begin{tabular}{|c|c|c|c|c|c|c|c|c|}
\hline \multirow{3}{*}{ Age at death } & \multicolumn{4}{|c|}{ Hospice versus hospital } & \multicolumn{4}{|c|}{ Home versus hospital } \\
\hline & \multirow[t]{2}{*}{$\mathbf{R R}$} & \multicolumn{2}{|l|}{$95 \% \mathrm{Cl}$} & \multirow[t]{2}{*}{$P$ value } & \multirow[t]{2}{*}{ RR } & \multicolumn{2}{|c|}{$95 \% \mathrm{Cl}$} & \multirow[t]{2}{*}{$P$ value } \\
\hline & & & & & & & & \\
\hline Neonate & 0.4 & 0.3 & 0.5 & & 0.2 & 0.2 & 0.3 & \\
\hline 28 days to 1 year & REF & & & & REF & & & \\
\hline $1-5$ years & 1.1 & 0.9 & 1.3 & $<0.001$ & 1.6 & 1.4 & 1.8 & $<0.001$ \\
\hline $6-10$ years & 1.1 & 0.9 & 1.3 & $<0.001$ & 2.2 & 1.9 & 2.5 & $<0.001$ \\
\hline $11-15$ years & 1.0 & 0.8 & 1.2 & 0.002 & 2.0 & 1.7 & 2.3 & $<0.001$ \\
\hline $16-20$ years & 0.7 & 0.6 & 0.8 & 0.242 & 1.7 & 1.5 & 1.9 & $<0.001$ \\
\hline $21-25$ years & 0.8 & 0.6 & 0.9 & 0.956 & 1.6 & 1.4 & 1.8 & $<0.001$ \\
\hline \multicolumn{9}{|l|}{ Sex } \\
\hline Male & REF & & & & REF & & & \\
\hline Female & 1.0 & 0.9 & 1.1 & 0.286 & 0.9 & 0.9 & 1.0 & 0.104 \\
\hline \multicolumn{9}{|l|}{ Ethnic group } \\
\hline White & REF & & & & REF & & & \\
\hline Black & 0.5 & 0.4 & 0.6 & $<0.001$ & 0.5 & 0.4 & 0.6 & $<0.001$ \\
\hline Pakistani & 0.3 & 0.3 & 0.4 & $<0.001$ & 0.5 & 0.5 & 0.6 & $<0.001$ \\
\hline Indian & 0.5 & 0.3 & 0.6 & $<0.001$ & 0.6 & 0.5 & 0.7 & $<0.001$ \\
\hline Bangladeshi & 0.3 & 0.2 & 0.6 & $<0.001$ & 0.6 & 0.4 & 0.8 & $<0.001$ \\
\hline Mixed/Chinese/other & 0.7 & 0.6 & 0.8 & $<0.001$ & 0.6 & 0.5 & 0.7 & $<0.001$ \\
\hline Missing & 0.6 & 0.5 & 0.8 & $<0.001$ & 0.7 & 0.6 & 0.9 & $<0.001$ \\
\hline \multicolumn{9}{|l|}{ Deprivation category } \\
\hline Category 1 -least deprived & REF & & & & REF & & & \\
\hline Category 2 & 1.0 & 0.8 & 1.1 & 0.529 & 1.0 & 0.9 & 1.1 & 0.952 \\
\hline Category 3 & 0.9 & 0.8 & 1.0 & 0.145 & 0.9 & 0.8 & 1.0 & 0.147 \\
\hline Category 4 & 0.9 & 0.8 & 1.0 & 0.054 & 0.9 & 0.8 & 0.9 & 0.01 \\
\hline Category 5-most deprived & 0.8 & 0.7 & 0.9 & 0.003 & 0.8 & 0.7 & 0.8 & $<0.001$ \\
\hline \multicolumn{9}{|l|}{ Government office region } \\
\hline London & REF & & & & REF & & & \\
\hline North-East & 0.7 & 0.6 & 1.0 & 0.047 & 1.7 & 1.4 & 1.9 & $<0.001$ \\
\hline North-West & 1.2 & 01.0 & 1.4 & 0.062 & 1.2 & 1.1 & 1.4 & 0.002 \\
\hline Yorkshire and Humber & 2.3 & 1.9 & 2.7 & $<0.001$ & 1.4 & 1.2 & 1.6 & $<0.001$ \\
\hline East Midlands & 1.0 & 0.8 & 1.3 & 0.933 & 1.1 & 1.0 & 1.3 & 0.118 \\
\hline West Midlands & 1.6 & 1.4 & 12.0 & $<0.001$ & 1.2 & 1.1 & 1.4 & 0.003 \\
\hline East of England & 1.8 & 1.5 & 2.1 & $<0.001$ & 1.4 & 1.2 & 1.6 & $<0.001$ \\
\hline South-East & 1.8 & 1.5 & 2.2 & $<0.001$ & 1.3 & 1.2 & 1.5 & $<0.001$ \\
\hline South-West & 1.7 & 1.4 & 2.1 & $<0.001$ & 1.4 & 1.3 & 1.6 & $<0.001$ \\
\hline \multicolumn{9}{|l|}{ Year of death } \\
\hline 2003-2007 & REF & & & & REF & & & \\
\hline 2008-2012 & 1.5 & 1.3 & 1.6 & $<0.001$ & 1.1 & 1.04 & 1.2 & 0.003 \\
\hline 2013-2017 & 1.7 & 1.5 & 1.9 & $<0.001$ & 1.2 & 1.07 & 1.3 & 0.003 \\
\hline \multicolumn{9}{|l|}{ Main diagnostic group } \\
\hline Congenital conditions & REF & & & & REF & & & \\
\hline Circulatory conditions & 0.3 & 0.2 & 0.5 & $<0.001$ & 0.6 & 0.5 & 0.7 & $<0.001$ \\
\hline Gastrointestinal conditions & 0.4 & 0.2 & 0.7 & 0.005 & 0.3 & 0.2 & 0.5 & $<0.001$ \\
\hline Genitourinary conditions & 0.4 & 0.3 & 0.6 & $<0.001$ & 0.6 & 0.5 & 0.7 & $<0.001$ \\
\hline Haematological conditions & 0.4 & 0.2 & 0.7 & 0.003 & 0.6 & 0.5 & 0.8 & 0.004 \\
\hline Metabolic conditions & 3.7 & 3.0 & 4.6 & $<0.001$ & 2.1 & 1.8 & 2.5 & $<0.001$ \\
\hline Neurological conditions & 2.0 & 1.7 & 2.3 & $<0.001$ & 1.3 & 1.2 & 1.5 & $<0.001$ \\
\hline Cancer & 4.4 & 43.8 & 5.1 & $<0.001$ & 4.0 & 3.6 & 4.4 & $<0.001$ \\
\hline Other conditions & 2.4 & 1.8 & 3.1 & $<0.001$ & 1.2 & 0.9 & 1.5 & 0.134 \\
\hline Perinatal conditions & 0.3 & 0.3 & 0.4 & $<0.001$ & 0.4 & 0.3 & 0.5 & $<0.001$ \\
\hline Respiratory conditions & 0.6 & 0.4 & 0.8 & 0.002 & 0.7 & 0.6 & 0.8 & $<0.001$ \\
\hline
\end{tabular}

NICE, National Institute for Health and Care Excellence; REF, reference group; RR, relative risk.

A lower percentage of white children died in hospital (69\%) when compared with the other ethnic groups where between $78 \%$ (Chinese/mixed/other) to $85 \%$ (Bangladeshi) died in hospital.
The highest percentage of deaths in hospital were in London $(77 \%)$ with the lowest in the South-West (69\%). Yorkshire and the Humber and the South-East had the highest percentage of hospice deaths (9\%) and the North-East the lowest (4\%). 
Conversely the highest percentage of home deaths was also in the North-East (23\%) and the lowest in London (12\%).

There is a linear trend with deprivation, the more deprived being more likely to die in hospital.

Table 2 shows the distribution of place of death by diagnostic category. The percentage of children with cancer who died in hospital was $44 \%$ with the next lowest metabolic at $61 \%$. Home deaths were also highest among children who had cancer (41\%) and were lowest among those who had perinatal conditions (2\%). Children with cancer (14\%), metabolic conditions (13\%), other conditions $(10 \%)$ or neurological conditions $(9 \%)$ had the highest percentage of hospice deaths.

The results of the multivariable multinomial logistic regression model comparing dying at home or in a hospice compared with dying in hospital are shown in table 3 . The reference group for comparison throughout this section is hospital.

Hospice versus hospital: Neonates were less likely than those aged 28 days to $<1$ year to die in hospice and those aged 1-10 years were more likely to die in a hospice than those aged 28 days to 1 year. However, those aged $11-25$ years were no more likely than the those aged 28 days to $<1$ year to die in a hospice.

Children from all the ethnic minority groups were significantly less likely to die in hospice with children of Bangladeshi origin being the least likely to die in a hospice (RR 0.3 , 95\% CI 0.2 to 0.6) compared with white children. Those in the most deprived group were also less likely to die in a hospice compared with the least deprived (RR $0.8,95 \%$ CI 0.7 to 0.9 ). There were some geographical differences, with those who died in Yorkshire and Humber more likely than those in London to die in a hospice (RR 2.3, 95\% CI 1.9 to 2.7). Those in the North-East were less likely than those in London to die in a hospice (RR 0.7, 95\% CI 0.6 to 1.00$)$.

Those who died after 2008 were more likely than those who died before 2008 to die in a hospice.

Children with a cancer (RR 4.4, 95\% CI 3.8 to 5.1), neurological (RR 2.0, 95\% CI 1.7 to 2.3) or metabolic (RR 3.7, 95\% CI 3.0 to 4.6 ) diagnosis were more likely than those with a congenital diagnosis to die in a hospice.

There are some similarities in the home versus hospice component of the model for sex, ethnic group, deprivation and trends over time. The key differences in this comparison were that all age groups over 1 year were more likely than the 28 days to $<1$ year old group to die at home. Children from all other regions were more likely than those living in London to die at home compared (including the North-East, RR 1.7, 95\% CI 1.4 to 1.9, in contrast to the results for hospice compared with hospital).

\section{DISCUSSION}

The majority of children with a life-limiting condition in England continue to die in a hospital setting. There is some evidence of an increase in hospice deaths since the government report 'Better Care, Better Lives' in $2008^{18}$ but there is still a relatively small number of deaths $(<200)$ in hospices each year. The most recent national children's hospice data collection showed that only $21 \%$ of their caseload who died, died in the hospice. ${ }^{19}$

A higher proportion died in hospital in the present study than in studies from other countries ${ }^{2021}$ which may not be surprising given the different models of provision of palliative care and funding of healthcare systems across the world. The proportion of deaths at home are similar to figures from the USA $(10.1 \%$ in 1989 rising to $18.2 \%$ in 2003$)^{22}$ and Portugal (19.4\%). ${ }^{23}$

Palliative care input has been associated with more children dying outside the hospital; a national study from England and
Wales of 7709 children who died after being discharged from paediatric intensive care units showed that children who had palliative care recorded at the time of discharge were eight times more likely to die in the community than children who were not referred to palliative care. ${ }^{11}$ Likewise the study by Chang et al, showed that those who had palliative care were less likely to die in hospital. ${ }^{20}$ A study from Germany showed that of children who received specialist paediatric palliative care, $84 \%$ died at home with $96 \%$ in their preferred place. ${ }^{24}$ The general consensus among studies to date is that home is the preferred place of death, although not all families prefer home deaths; preferences vary over time and the research base consists of small studies which were prone to selection bias. ${ }^{10}$

Children with cancer were much more likely than other children to die at home or in a hospice. In England, children with cancer are treated and managed under a different model of care with palliative care being provided by specialists, including the paediatric oncology outreach nurses in most principal treatment centres. ${ }^{25}$ A recent national study showed that from 1993 to 2014, among children who died from cancer in England, those dying at home remained static at approximately 40\%; hospital deaths decreased slightly from $>50 \%$ to $45 \%$ and hospice deaths increased from $6 \%$ to $13 \% .^{26}$ An international study ${ }^{21}$ highlighted large variations in place of death between countries and that children with conditions other than cancer were less likely to die at home.

Age has been shown in several studies to be associated with dying at home with infants less likely than older children to die outside hospital. $^{22} 27$ The predominance of hospital death in the neonatal group may highlight the unpredictability of their prognosis and the additional challenges of offering choice of place of death in neonatal care. ${ }^{28}$

This study highlighted the differences in place of death for children from a minority ethnic group. This has been shown in other studies. $^{2026}$ There is little evidence on preferences of place of care in these populations and differences could possibly be due to access to healthcare services, divergent cultural attitudes or differing levels of financial or social support within a patient's family or social network. ${ }^{22}$ Importantly, services must be flexible enough to meet the needs of all children and their families. ${ }^{17} 29$

\section{Strengths and limitations}

This study used a whole population data set to identify children with a life-limiting condition and national death registration records. There can be delays in the registration of deaths for children if the coroner is involved so the recent years of data may be incomplete.

It was not possible to identify those children who had and had not received palliative care prior to death. There were no data on preferred place of death available for this cohort of children.

\section{CONCLUSIONS}

Despite small increases in hospice deaths over the last 15 years the vast majority of children with a life-limiting condition die in the hospital setting. Further research is needed on preferences for place of death especially in children with conditions other than cancer. Paediatric palliative care services should be funded adequately to enable equal access across all settings, diagnostic groups and geographical regions.

Twitter Stuart William Jarvis @swjarvis and Lorna K Fraser @lornafraser10

Contributors DG-S, SWJ, LKF have all made a substantial contribution to the concept or design of the work; or acquisition, analysis or interpretation of data; drafted the article or revised it critically for important intellectual content; approved 
the version to be published; and have participated sufficiently in the work to take public responsibility for appropriate portions of the content.

Funding This research was funded by the Martin House Research Centre (REF 2019_08). SWJ is funded by a National Institute for Health Research (NIHR) Doctoral Research Fellowship (award DRF-2018-11-ST2-013) for this research project. LKF is funded by a National Institute for Health Research (NIHR) Career Development Fellowship (award CDF-2018-11-ST2-002) for this research project. This publication presents independent research funded by the National Institute for Health Research (NIHR). The views expressed are those of the authors and not necessarily those of the NHS, the NIHR or the Department of Health and Social Care.

Competing interests None declared.

Patient consent for publication Not required.

Ethics approval This study was approved by NHS Digital and the ONS microdata release panel (IGARD ref NIC-379681), and NHS REC (ref 16/EM/0013).

Provenance and peer review Not commissioned; externally peer reviewed.

Data availability statement Data may be obtained from a third party and are not publicly available. Data are available from NHS Digital.

Supplemental material This content has been supplied by the author(s). It has not been vetted by BMJ Publishing Group Limited (BMJ) and may not have been peer-reviewed. Any opinions or recommendations discussed are solely those of the author(s) and are not endorsed by BMJ. BMJ disclaims all liability and responsibility arising from any reliance placed on the content. Where the content includes any translated material, BMJ does not warrant the accuracy and reliability of the translations (including but not limited to local regulations, clinical guidelines, terminology, drug names and drug dosages), and is not responsible for any error and/or omissions arising from translation and adaptation or otherwise.

Open access This is an open access article distributed in accordance with the Creative Commons Attribution 4.0 Unported (CC BY 4.0) license, which permits others to copy, redistribute, remix, transform and build upon this work for any purpose, provided the original work is properly cited, a link to the licence is given, and indication of whether changes were made. See: https://creativecommons.org/ licenses/by/4.0/.

\section{ORCID iDs}

Stuart William Jarvis http://orcid.org/0000-0001-8447-0306

Lorna K Fraser http://orcid.org/0000-0002-1360-4191

\section{REFERENCES}

1 Office for National Statistics. Mortality statistics: deaths registered in England and Wales by area of usual residence, 20122014.

2 Sidebotham P, Fraser J, Fleming P, et al. Child death in high-income countries 2 patterns of child death in England and Wales. Lancet 2014;384:904-14. Online.

3 Bristol. Together for Short Lives. A Guide to Children's Palliative Care 2018.

4 Noyes J, Edwards RT, Hastings RP, et al. Evidence-Based planning and costing palliative care services for children: novel multi-method epidemiological and economic exemplar. BMC Palliat Care 2013;12:18

5 Villanueva G, Murphy MS, Vickers D, et al. End of life care for infants, children and young people with life limiting conditions: summary of NICE guidance. BMJ 2016;355:i6385.
6 National Institute for Health and Care Excellence (NICE). End Fo life care for infants, children and young people; quality Standards. London, 2017: 160.

7 Health. Do.. End of life care strategy: fourth annual report.: department of health 2012.

8 Bluebond-Langner M, Beecham E, Candy B, et al. Preferred place of death for children and young people with life-limiting and life-threatening conditions: a systematic review of the literature and recommendations for future inquiry and policy. Palliat Med 2013:27:705-13.

9 Pollock K. Is home always the best and preferred place of death? BMJ 2015;351:351. 10.1136/bmi.h4855 [published Online..

10 Johnston EE, Martinez I, Currie E, et al. Hospital or home? where should children die and how do we make that a reality? J Pain Symptom Manage 2019 (published Online First: 2019/12/31).

11 Fraser LK, Fleming S, Parslow R. Changing place of death in children who died after discharge from paediatric intensive care units: a national, data linkage study. Palliat Med 2018;32:337-46.

12 Centre. HSCl. A Guide to Linked Mortality Data from Hospital Episode Statistics and the Office for National Statistics.: Health \& Social Care Information Centre 2015.

13 NHS Digital. Hospital Accident \& Emergency Activity. NHS Digital.

14 Fraser LK, Miller M, Hain R, et al. Rising national prevalence of life-limiting conditions in children in England. Pediatrics 2012;129:e923-9. 6 [published Online.

15 NOMIS. Census 2011 - Ethnic group by sex by age 2011.

16 Government. DfCaL. Indices of multiple deprivation 2011.

17 Fraser LK, Jarvis SW, Moran N, et al. Children in Scotland requiring palliative care: identifying numbers and needs (the ChiSP study. York, UK: University of York, 2015.

18 Lewis M. Better care, better lives. improving outcomes for children young people and their families living with life limiting and life threatening conditions. Department of Health, 2008.

19 Devanney C, Bradley S. Count Me In: Children's Hospice Service Provision, 2011/12. Bristol: Together for Short Lives, 2012.

20 Chang E, MacLeod R, Drake R. Characteristics influencing location of death for children with life-limiting illness. Arch Dis Child 2013;98:419-24.

21 Håkanson C, Öhlén J, Kreicbergs U, et al. Place of death of children with complex chronic conditions: cross-national study of 11 countries. Eur $J$ Pediatr 2017:176:327-35.

22 Feudtner C, Feinstein JA, Satchell M, et al. Shifting place of death among children with complex chronic conditions in the United States, 1989-2003. JAMA 2007; 297:2725-32

23 Forjaz de Lacerda A, Gomes B. Trends in cause and place of death for children in Portugal (a European country with no paediatric palliative care) during 1987-2011: a population-based study. BMC Pediatr 2017;17:215.

24 Bender HU, Riester MB, Borasio GD, et al. "Let's Bring Her Home First." Patient Characteristics and Place of Death in Specialized Pediatric Palliative Home Care. J Pain Symptom Manage 2017;54:159-66 https://doi.org/

25 England. N. Service Specification for Children's Cancer services 2018.

26 Gao W, Verne J, Peacock J, et al. Place of death in children and young people with cancer and implications for end of life care: a population-based study in England, 1993-2014. BMC Cancer 2016:16:16.

27 Jarvis S, Parslow RC, Carragher P, et al. How many children and young people with life-limiting conditions are clinically unstable? a national data linkage study. Arch Dis Child 2017;102:131-8.

28 Craig F, Mancini A. Can we truly offer a choice of place of death in neonatal palliative care? Semin Fetal Neonatal Med 2013;18:93-8 https://doi.org/

29 National Palliative and End of Life Care Partnership. Ambitions for palliative and end of life care: a national framework for local action 2015-2020 2015. 